\title{
Effect of improved sol-gel method on composition and micro morphology of $\mathrm{Ca}_{3} \mathrm{Co}_{4} \mathrm{O}_{9}$
}

\author{
Xuanye $\mathrm{Hu}^{1,2}$, Yanan $\mathrm{Li}^{1,2}$, Ping $\mathrm{Wu}^{1,2, *}$, Shiping Zhang ${ }^{1,2}$, and Xiulan Huai ${ }^{3}$ \\ ${ }^{1}$ University of Science and Technology Beijing, School of mathematics and Physics, Beijing 100083, China \\ ${ }^{2}$ Beijing Key Laboratory for Magneto-Photoelectrical Composite and Interface Science, Beijing 100083, China \\ ${ }^{3}$ Chinese Academy of Sciences, Institute of Engineering Thermophysics, Beijing 100190, China
}

\begin{abstract}
Ca}_{3} \mathrm{Co}_{4} \mathrm{O}_{9}$ is a potential high temperature thermoelectric material. We explore the hydrothermal treatment improved sol-gel method to prepare $\mathrm{Ca}_{3} \mathrm{Co}_{4} \mathrm{O}_{9}$ thermoelectric materials. We find that this treatment can increase the thermoelectric performance of the samples compared with the conventional citric acid sol-gel method. We also find the samples prepared by the improved sol-gel method have more uniform grain distribution, better densification, and less voids. At about $1000 \mathrm{~K}$, compared with the conventional sol-gel method, the power factor of the samples prepared by improved sol-gel method improves about $168 \%$.
\end{abstract}

\section{Introduction}

In recent years, due to the need of environmental protection and energy saving, thermoelectric materials have been paid more and more attention[1]. Thermoelectric oxides, which have the advantages of high stability under high temperature, no oxidation problem, no pollution, long service life and simple fabrication, have become an attractive research topic in the thermoelectric field. Especially, $\mathrm{Ca}_{3} \mathrm{Co}_{4} \mathrm{O}_{9}$ becomes a strong candidate for high temperature applications. Its stability is better compared with the prior $\mathrm{NaCO}_{2} \mathrm{O}_{4}$ single crystal[2] for it can maintain its stable performance under more than $1100 \mathrm{~K}$ in the air[3].

There are many methods to prepare $\mathrm{Ca}_{3} \mathrm{Co}_{4} \mathrm{O}_{9}$, including solid state reaction method[4,5], sol-gel method[6-9], hydrothermal method and the like. In the solid state reaction, $\mathrm{Ca}_{3} \mathrm{Co}_{4} \mathrm{O}_{9}$ is obtained directly at high temperature from the dry mixture of $\mathrm{CaO}$ and $\mathrm{CoO}$ in a stoichiometric ratio(3:4). This method is simple but the grain size is big and the reaction temperature has a great influence on the composition of final product. Sol-gel method is to treat the mixture of $\mathrm{Ca}\left(\mathrm{NO}_{3}\right)_{2}$ and $\mathrm{Co}\left(\mathrm{NO}_{3}\right)_{2}$ through solution, sol, gel, and then heat treatment to obtain $\mathrm{Ca}_{3} \mathrm{Co}_{4} \mathrm{O}_{9}$. Hydrothermal method can obtain $\mathrm{Ca}_{3} \mathrm{Co}_{4} \mathrm{O}_{9}$ by mixed solution of $\mathrm{Ca}\left(\mathrm{NO}_{3}\right)_{2}$ and $\mathrm{Co}\left(\mathrm{NO}_{3}\right)_{2}$ at certain temperature and pressure. The samples prepared by sol-gel method and hydrothermal method have a smaller grain size and more uniform distribution relative to the solid state reaction method, and these two factors are considered to be the key to improve the thermoelectric performance[10]. We speculate that the solution environment at high temperature and high pressure has an effect on the property of the samples. Therefore, we attempt to transfer the sol-gel process into the reactor, which is the difference between conventional sol-gel method and the improved sol-gel method.

In this work, the composition, structure and micromorphology of the samples prepared by improved sol-gel method are investigated by comparing with those of the conventional method. Furthermore, the thermoelectric performance of the samples is investigated as well.

\section{Experiment details}

\subsection{Preparation of $\mathrm{Ca}_{3} \mathrm{Co}_{4} \mathrm{O}_{9}$ powders by conventional sol-gel method}

$\mathrm{Ca}_{3} \mathrm{Co}_{4} \mathrm{O}_{9}$ powders were prepared by conventional solgel method. A mixture of $\mathrm{Ca}\left(\mathrm{NO}_{3}\right)_{2} \cdot 4 \mathrm{H}_{2} \mathrm{O}$, $\mathrm{Co}\left(\mathrm{NO}_{3}\right)_{2} \cdot 6 \mathrm{H}_{2} \mathrm{O}$ in a stoichiometric ratio $(3: 4: 7.7)$ was dissolved and thoroughly stirred in a citric acid solution. After that the solution was stirred by a magnetic mixer and heated at $80^{\circ} \mathrm{C}$ until the wet gel was formed. Later the wet gel was dried at $120^{\circ} \mathrm{C}$ in oven to get the dry gel. The dry gel was manually milled and then calcined at $750^{\circ} \mathrm{C}$ for 2 hours in air. The powder were manually milled once more and uniaxially pressed at $30 \mathrm{MPa}$ to form pellets and sintered at $900^{\circ} \mathrm{C}$ for 3 hours to get the $\mathrm{Ca}_{3} \mathrm{Co}_{4} \mathrm{O}_{9}$ bulk samples.

\footnotetext{
Corresponding author: pingwu@sas.ustb.edu.cn
} 


\subsection{Preparation of $\mathrm{Ca}_{3} \mathrm{Co}_{4} \mathrm{O}_{9}$ powders by improved sol-gel method}

$\mathrm{Ca}_{3} \mathrm{Co}_{4} \mathrm{O}_{9}$ powders were prepared by improved sol-gel method. A mixture of $\mathrm{Ca}\left(\mathrm{NO}_{3}\right)_{2} \cdot 4 \mathrm{H}_{2} \mathrm{O}, \mathrm{Co}\left(\mathrm{NO}_{3}\right)_{2} \cdot 6 \mathrm{H}_{2} \mathrm{O}$ in a stoichiometric ratio $(3: 4: 7.7)$ was dissolved and thoroughly stirred in a citric acid solution. After that the solution was stirred by a magnetic mixer and heated at $80^{\circ} \mathrm{C}$ until the sol was formed. Later the sol was transferred into a hydrothermal reactor and the reactor was placed into oven. After heated at a constant temperature for a period of time, the mixture in the reactor was filtered to get the sediment. Next the sediment was dried in drying baker at $120^{\circ} \mathrm{C}$ for $5 \mathrm{~h}$ to get rid of the deionized water and volatile organic. Then it was manually milled and heated at $900^{\circ} \mathrm{C}$ for 2 hours to obtain the precursor powder of $\mathrm{Ca}_{3} \mathrm{Co}_{4} \mathrm{O}_{9}$. Finally, the powder was pressed into planchet under $30 \mathrm{Mpa}$ and sintered at $900^{\circ} \mathrm{C}$ for 3 hours to get the $\mathrm{Ca}_{3} \mathrm{Co}_{4} \mathrm{O}_{9}$ bulk samples.

\subsection{Characterization of samples}

The phase was analyzed by X-ray diffraction instrument (Rigaku,Japan) with $\mathrm{Cu} \mathrm{K \alpha}$ radiation, the range of scanning angle is $5^{\circ} \sim 90^{\circ}$ and the scan rate is $0.03^{\circ} / \mathrm{s}$. The morphology of the samples was observed by scanning electron microscope (Zeiss Supra 55). The Seebeck coefficient and the electrical conductivity of the samples were measured by instrument SBA 458.

\section{Results and discussion}

\subsection{XRD analysis}

The X-ray powder diffraction patterns of all the samples are shown in Fig.1. The peak positions of all samples can be matched with the standard JCPDS card (23-0110) of $\mathrm{Ca}_{3} \mathrm{Co}_{4} \mathrm{O}_{9}$ and (21-0139) of $\mathrm{Ca}_{9} \mathrm{Co}_{12} \mathrm{O}_{28}$. The XRD patterns show the compositions of the samples prepared by the conventional sol-gel method and improved sol-gel method are almost the same. They are both composed of $\mathrm{Ca}_{3} \mathrm{Co}_{4} \mathrm{O}_{9}$ and $\mathrm{Ca}_{9} \mathrm{Co}_{12} \mathrm{O}_{28}$, with no other impurity phase.

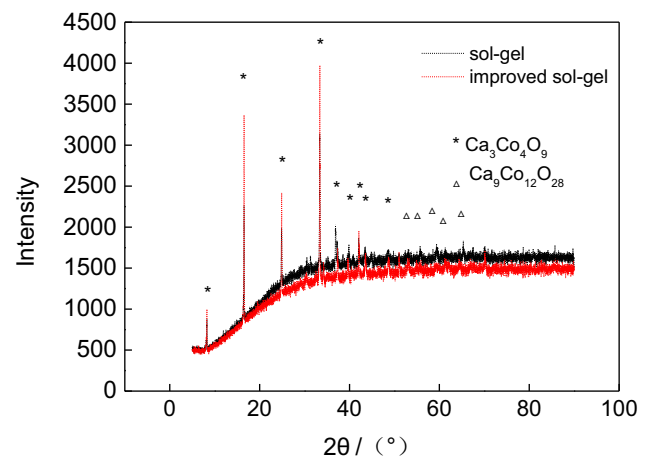

Fig.1. XRD patterns of two powders.
Furthermore, the relationship between $\mathrm{Ca}_{3} \mathrm{Co}_{4} \mathrm{O}_{9}$ and $\mathrm{Ca}_{9} \mathrm{Co}_{12} \mathrm{O}_{28}$ equals to the relationship between single crystal and polycrystalline and $\mathrm{Ca}_{9} \mathrm{Co}_{12} \mathrm{O}_{28}$ can usually be expressed as $\mathrm{Ca}_{3} \mathrm{Co}_{4} \mathrm{O}_{9+\delta}$. In conclusion, improved solgel method can be used to prepare the $\mathrm{Ca}_{3} \mathrm{Co}_{4} \mathrm{O}_{9}$ samples.

\subsection{SEM analysis}

Fig.2(a) is the SEM image of the sample prepared by the conventional sol-gel method, and Fig.2(b) is the SEM image of the sample prepared by the improved sol-gel method. Fig.2. shows that the grain size are about the same size, near $1 \mu \mathrm{m}$. In contrast, the grain size of the samples prepared by improved sol-gel is more uniform, which will improve the thermoelectric performance of materials. As is shown in Fig.2., the places whose color is deeper than the surrounding are voids. And the voids of Fig.2(a) is more than that of the Fig.2(b), which leads to the decrease in carrier mobility, and then decreases the electrical conductivity of the sample.

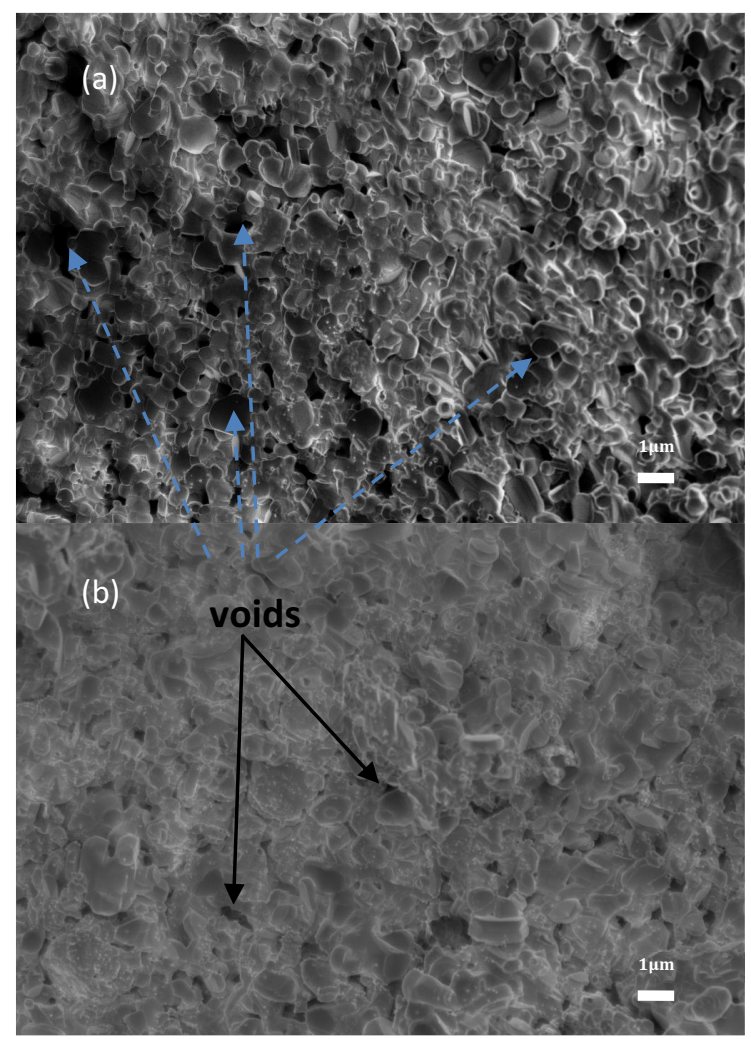

Fig.2. SEM spectra of two powders. [ (a) is prepared by the conventional sol-gel method, (b) is prepared by improved solgel method.]

\subsection{Thermoelectric performance analysis}

We analyzed the thermoelectric performance of three different samples. The first sample, which is name after "ISM1", was prepared by improved sol-gel method and the oven was set to $200^{\circ} \mathrm{C}$ and $48 \mathrm{~h}$. Compared with the first one, the second sample, which is name after "ISM2", was prepared by improved sol-gel method as well, but 
the oven was set to $150^{\circ} \mathrm{C}$ and $12 \mathrm{~h}$. The third sample was prepared by conventional sol-gel method and named for "CSM".

\subsubsection{Conductivity analysis}

Fig.3. shows the curves of electric conductivity of different samples varies with temperature, the curves "ISM1" and "ISM2" are higher than the curve "CSM" at the same temperature. For the same temperature, the factors that influence the conductivity of the material are the carrier concentration and the carrier mobility. Hydrothermal treatment is to give a higher temperature and pressure, which will increase the carrier concentration of the samples. Combined with SEM image, the smaller void ratio makes the sample more dense, thereby increasing the carrier mobility. Therefore, improved sol-gel method does improve the conductivity of the sample.

It's surprising that different conditions of oven change the performance of the samples from semiconductor to metal. For the curve of "ISM1", the electrical conductivity decreases with the increase of temperature, which presents a metallic property. On the contrary, the curve of "ISM2" binding upward with the increase of temperature, presents a semiconductor property. This shows that the temperature has impacts on the conductivity of the sample, and can even changes in its performance irreversibly.

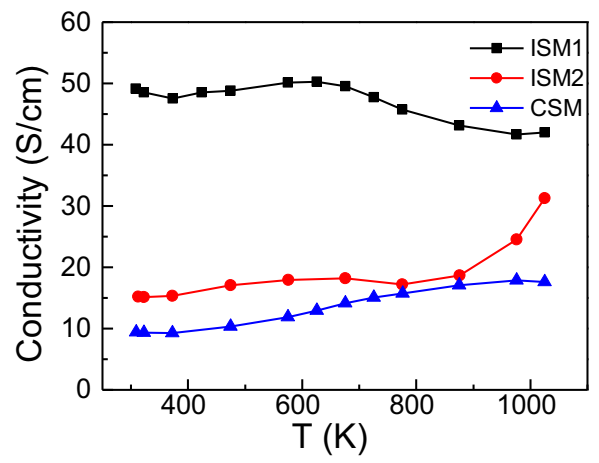

Fig.3.Temperature dependence of conductivity of all samples.

\subsubsection{Seebeck coefficient analysis}

The Seebeck coefficient of a material is a measure of the magnitude of an induced thermoelectric voltage in response to a temperature difference across that material, as induced by the Seebeck effect. Physically, the magnitude and sign of the Seebeck coefficient can be approximately understood as being given by the entropy per unit charge carried by electrical currents in the material. It may be positive or negative. In conductors that can be understood in terms of independently moving, nearly-free charge carriers, the Seebeck coefficient is negative for negatively charged carriers (such as electrons), and positive for positively charged carriers (such as electron holes). The maximum characteristics of thermoelectric materials is the transformation between heat and electric, so the measurement of Seebeck coefficient which can reflect the thermoelectric conversion is necessary.

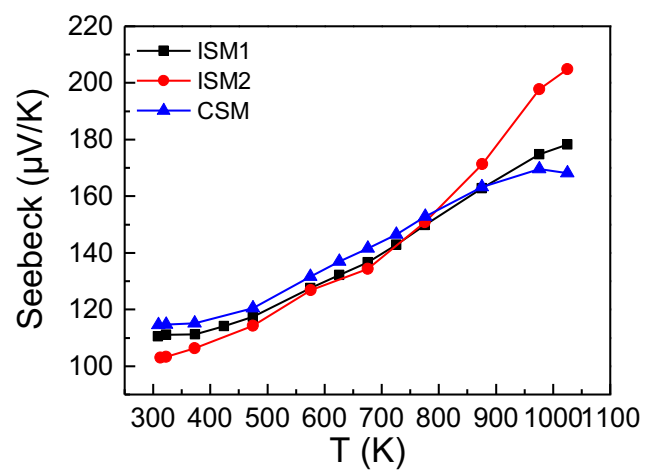

Fig.4. Temperature dependence of Seebeck coefficient of all samples.

Fig.4. shows the curves of Seebeck coefficient of different samples varies with temperature. All samples exhibit positive Seebeck coefficient indicating their hole carrier conduction, and the $\mathrm{Ca}_{3} \mathrm{Co}_{4} \mathrm{O}_{9}$ sample is p-type semiconductor. The Seebeck coefficient of three samples increases with the increasing temperature. In contrast, the Seebeck coefficient of the samples prepared by improved sol-gel method are slightly higher.

\subsubsection{Power factor analysis}

Power factors, equals the product of the square of the Seebeck coefficient and the electrical conductivity. Fig.5. shows the curves of power factor of different samples varies with temperature.

The power factors of "ISM1" and "ISM2" reach $1.335 \times 10^{-4} \mathrm{~W} / \mathrm{m} \cdot \mathrm{K}^{2}$ at $1000 \mathrm{~K}$, but that of "CSM" reaches $4.970 \times 10^{-5} \mathrm{~W} / \mathrm{m} \cdot \mathrm{K}^{2}$ at the same temperature. By contrast, the power factor of the sample prepared by improved method increased about $168 \%$ at $1050 \mathrm{~K}$.

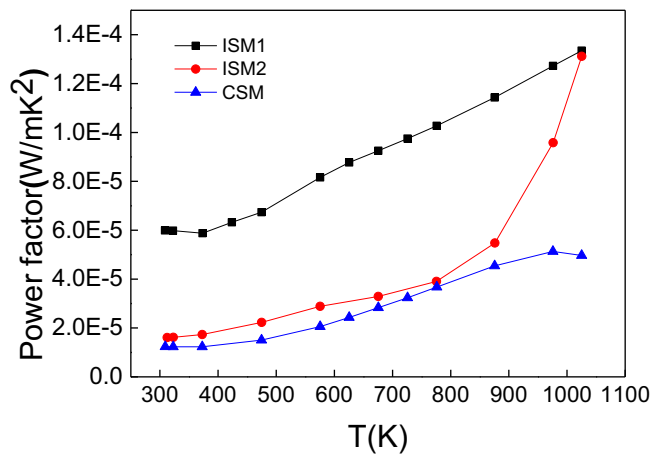

Fig.5. Temperature dependence of power factor of all samples.

\section{Conclusion}

We prepared the powders of $\mathrm{Ca}_{3} \mathrm{Co}_{4} \mathrm{O}_{9}$ by the 
hydrothermal treatment improved sol-gel method and the conventional citric acid sol-gel method. The following conclusions are obtained by the characterization of the phase composition, microstructure and thermoelectric performance of the material: (1) The samples prepared by the two methods are both composed of $\mathrm{Ca}_{3} \mathrm{Co}_{4} \mathrm{O}_{9}$. (2) Compared with the sample prepared by the conventional sol-gel method, $\mathrm{Ca}_{3} \mathrm{Co}_{4} \mathrm{O}_{9}$ thermoelectric material prepared by improved sol-gel method has more uniform grain distribution, better densification, and less voids, which lead to the increase of carrier mobility rate and conductivity; Seebeck coefficient has little change; The power factor of each temperature is increased. At about $1000 \mathrm{~K}$, compared with the conventional sol-gel method, the samples prepared by improved sol-gel method were improved by $168 \%$.

We acknowledge the National Natural Science Foundation of China for financial support (No. 51476173).

\section{References}

1. F.J. Disalvo, Science 285, 703(1999).

2. Terasaki I, Sasago Y, Uchinokura K, Phys Rev B 56, 12685-12687(1997).

3. Woermann E, Muan A, J Inorg Nucl Chem 32, 1455-1459(1970).

4. Kohei Obata, Yasunori Chonan, Takao Komiyama, et al, Journal of Electronic Materials 42, 22212226(2013).

5. Bhaskar A, Huang Y.C, Liu C.J, et al. Journal of Electronic Materials 43, 535-540(2013)

6. S. Pinitsoontorn, N. Keawprak, N. Lerssongkram, et al. J Mater Sci: Mater Electron 23,1050-1056 (2012).

7. Song Chen, Yun Chen, Xueyan Song, et al. J SolGel Sci Technol 64, 627-636(2012).

8. F.P. Zhang, Q.M. Lu, J.X. Zhang. Physica B 404, 2142-2145(2009).

9. Jie Xu, Changping Wei, Kun Jia. Journal of Alloys and Compounds 500,227-230(2010).

10. S. Pinitsoontorn, N. Lerssongkram, A. Harnwunggmoung, et al, Journal of Alloys and Compounds 503, 431-435 (2010). 